\title{
Is "Partners" (Cooperative Teaching and Learning) Method an effective Innovative teaching method for Arab Nursing Students?
}

\author{
Mrs. Lakshmi Renganathan ${ }^{1}$, Dr. Salem Al Touby ${ }^{2}$, \\ Mrs.ShanthiRamasubramaniam ${ }^{3}$, \\ 1. Assistant Tutor, Oman Nursing Institute, Muscat 2. Dean, Oman Nursing Institute, Muscat, 3.PhD scholar of \\ Asia e University, Malaysia
}

\section{Introduction}

The global goal of the nurse educators is to develop initiatives and innovations which will prepare the nursing graduates for quality nursing practice. Faculty must help future nurse professionals to become selfdirected learners and knowledgeable participants in Evidence Based Practice.

Damodaran (2007) emphasize that the "Innovation" is effective in terms of gain of knowledge, than the standard. Many academic institutions use the conventional method of teaching, which are ineffective in comparison with newer technologies in terms of motivations. Individualized instructions are student centered. Programmed instruction is effective in terms of gain of knowledge, than the standard. Alternative approaches to teaching learning to be used in order to motivate students to explore and understand issues in depth.

On the other hand, Biggs (2006) explores that basically innovative teaching must include two major components sending and receiving information. Ultimately the goal of the education system is to impart knowledge the most appropriate way as per the need and time. Therefore any communication that serves its purpose without diluting the core of the subject could be considered as most appropriate method. Faculties are challenged to capture the attention of the learner, to focus on what the learner knows, and to engage students in their own individual learning experiences.

Furthermore Bradshaw (2001) discusses innovative teaching can range from simple to complex. Innovations can be developed for an exercise within a course or for entire course is taught. It can be developed for the whole programmes or for a whole school. This can be prepared by one faculty or by a team of faculty. In all the above the learning needs of the students should be considered as prime important.

Experts agree that the use of innovative approach will help to meet the demands of today's students and society (Lois et al., 2009).Research based on anecdotal evidence of the outcomes of innovative teaching includes the development of critical thinking and problem solving technique, teamwork and collaborative skills, communication skills and dedication to lifelong learning (Amos and White 1998, Bowles 2000).Cooperative is one of the innovative teaching strategies can be incorporated in the nursing curriculum for the better results.

A cooperative Learning environment exists if all of these five basic elements present (Johnson \& Johnson, 2002)

- Positive Reliance on the other group members

- Significant, constructive face- to- face interaction.

- All members must individually succeed.

- Constant use of small group skills.

- Continually learning group skills aimed at improving future effectiveness.

The cooperative learning is widely used in schools but it can be used with all ages and for all subjects (Sapon, 2002). Robert Slavin at John Hopkins University reported highly positive results on CTL. He summarized after analyzing 90 students that achievement under cooperative learning structures was significantly positive. $\mathrm{He}$ concluded that cooperative methods can be an effective means of increasing student achievement but only if they incorporate group goals and individual accountability (Slavin, 1995).

In a cooperative learning classroom student's work together to attain group goal that cannot be obtained by working alone or competitively. In this classroom structure, students discuss subject matter, help each other learn and provide encouragement for member of the group (Johnson and Johnson, 2000).Linda, (1995) reaffirms that the co operative learning as an instructional methodology provides opportunities for students to develop skills in group interactions and in working with others that are needed in today's world. Slavin, 1995 argues that there are two theoretical perspectives related to co operative learning namely motivational and cognitive. Several studies have investigated the effects of cooperative learning methods on student learning which yields positive effects on student achievement and retention of information (Johnson and Johnson 1990).In a review of 46 studies related to cooperative learning it was found that this learning resulted in significant positive effects in $63 \%$ of the studies and only two studies reported higher achievement for the 
comparison group (Slavin 1991). Johnson et al., 2000 conducted Meta analysis of 122 studies related to co operative learning and concluded that there was strong evidence for the superiority of cooperative learning in promoting achievement over competitive and individualistic strategies.

Similarly the psychologist at the University of Michigan reviewed more than 500 research studies pertaining to teaching and learning in college classrooms. When the students were asked, what is the most effective teaching method; the answers were it depends on the goal, the student, the content, and the teacher but the next best answer was "student teaching the other students" (Mujibul 2008). CTL is strongly based on this concept of student teaching other student.

Brady (2010) scrutinized the students those who were fully participated in group activities, exhibited collaborative behaviors, provided constructive feedback and cooperated with their group had a higher likelihood of receiving higher test scores and course grades at the end of the semester. Results from this study support the notion that cooperative learning is an active pedagogy that fosters higher academic achievement.

The need for the present study was focused mainly based on the following suggestions. Firstly, nurse educators should consider new approaches to teaching for several reasons. The National League for Nursing's (NLN) position statement in 2003, Vision of Nursing Education, encourages nurse educators to develop strategies that develop critical thinking in students. Further the aim of education should be on the process of thinking and involve being proactive, collaborative and quality oriented (Forneris, 2004). Secondly, the increased complexities of clinical practice and vast amount of nursing theory require the student to solve problems in a safe and effective manner (Beers 2005,Pardue et al., 2005).Thirdly, the Director General of Education and Training, Ministry of Health, Sultanate of Oman clearly mentions in its Mission statement as "DGET provides high standard education and training to meet the health needs and expectations of the society by offering innovative educational programs, continuing professional education, scholarship and research that promote life long learning" (DGET,2010).

Despite of many literatures found in the other discipline proving that CTL method is effective, regrettably there are very few studies found in nursing fraternity. Therefore here an attempt is made to understand the contribution of the "Partners" method on the $2^{\text {nd }}$ and $3^{\text {rd }}$ year nursing student's academic performance. Furthermore this method was compared between both $2^{\text {nd }}$ and $3^{\text {rd }}$ year nursing students.

Aim

The study aimed to identify the effectiveness of the new cooperative teaching learning technique "Partners" on nursing subjects and to compare this method between $2^{\text {nd }}$ and $3^{\text {rd }}$ year General Nursing Diploma Students at Oman Nursing Institute, Muscat at Sultanate of Oman.

\section{Research Questions}

1. Dose the "Partners" method effective on "Nursing care of patients with Osteo Arthritis" for $2^{\text {nd }}$ year General Nursing Diploma students at Oman Nursing Institute, Muscat?

2. Dose the "Partners" method effective on "Nursing care of children with gastro intestinal disorders" for $3^{\text {rd }}$ year General Nursing Diploma students at Oman Nursing Institute, Muscat?

3. Does the "Partners" method is more effective in $2^{\text {nd }}$ year compared with $3^{\text {rd }}$ year Arab nursing students?

Method

\section{Population and Setting}

The Oman Nursing Institute is a teaching institution which functions under Directorate General of Education and Training Department (DGET) of Ministry of Health. The General Nursing Diploma is a three years course. The $2^{\text {nd }}$ year nursing students (162) who were undergoing Adult health nursing course and the $3^{\text {rd }}$ year nursing students (127) were undertaking Child health nursing course was chosen for the study. The Omani Arab nationals are studying in this institution. The Interrupted Time Series Design which is categorized under Quasi Experimental Design (One group Post test Design) was adopted for the study. There was no sampling technique used. The total population was included for the study. The students studying in $2^{\text {nd }}$ and $3^{\text {rd }}$ year General Nursing Diploma programme at Oman Nursing Institute was chosen for the study.

\section{Intervention}

Ethical committee approval was obtained from the Research and Ethical Review Committee of Ministry of Health in Oman. An official permission obtained from the Dean of Oman Nursing Institute. The students undertaking child health nursing course and adult health nursing course was introduced to the "Partners" method. The topics for this method; nursing care of children with Gastro intestinal disorders for 3 rd year students and the nursing care of patients with Osteoarthritis for $2^{\text {nd }}$ year students respectively were chosen for the study. 
The "Partners" method was instituted in the following way. The students in each class room (30-34) were divided into five to six groups. These five-six groups were further subdivided. In each group, the leaders and partners were chosen. The content of the topic was categorized under the segments and given to each group. Half of each team is given an assignment to master the content to teach others in the group (Answering group).The groups were moved to one side of the room. The other half were given a responsibility to share and teach the information in the same above fashion and they were supposed to prepare questions for each segment.(Questioning group).Partners work /learn and co consults other partners working on the same material. The oral quiz was conducted by the questioning group and answered by the answering group. The teacher was the facilitator/moderator for the entire session including the oral quiz. The oral quiz was not graded. The students completed the entire session in 1-3 hours depending on their topics. Further clarification and discussion was done. 15 more minutes were given for them to wind up. The leaders have given complete written report in detail and recorded what went on in each group. The students explained to each other in their own language (Arabic) and had fun. It was expressed by the students that they all enjoyed the session thoroughly (Kagan Spencer, 1994). After one week the written quiz was conducted on the same topic. This mock (written) quiz was graded and taken for evaluation.

\section{Data analysis}

The effect of this new method (Partners) was analyzed through descriptive statistics and $\mathrm{z}$ tests for comparison of the $2^{\text {nd }}$ and $3^{\text {rd }}$ year students. The effect of teaching method was assessed by performance of students in the mock (written) quiz.

\section{Results}

Most of the nursing student participants (98 percent) were in the age range of 20-25 years. Most of them were (85.1 percent) were females however the male population is also considerably higher (14.9 percent). Majority of them are single (96.5 percent) and rest were (3.5) married. None of them were widow, widower or divorcee.

TABLE: 1

Comparison of written quiz scores of "Partners" method of $2^{\text {nd }}$ and $3^{\text {rd }}$ year General Nursing Diploma Students

\begin{tabular}{|c|c|c|c|c|c|}
\hline Grade & Percentage & $\begin{array}{l}\text { 2nd year } \\
\text { students }\end{array}$ & Percentage & $\begin{array}{l}\text { 3rd year } \\
\text { students }\end{array}$ & Percentage \\
\hline A & $90-100$ & 66 & 40.74 & 25 & 19.68 \\
\hline $\mathrm{A}^{-}$ & $85-<90$ & 0 & 0 & 19 & 14.96 \\
\hline $\mathrm{B}^{+}$ & $81-<85$ & 0 & 0 & 0 & 0 \\
\hline $\mathrm{B}$ & $78-<81$ & 34 & 20.98 & 24 & 18.89 \\
\hline $\mathrm{B}^{-}$ & $75-<78$ & 0 & 0 & 0 & 0 \\
\hline $\mathrm{C}^{+}$ & $71-<75$ & 0 & 0 & 11 & 8.6 \\
\hline $\mathrm{C}$ & $68-<71$ & 21 & 12.96 & 0 & 0 \\
\hline $\mathrm{C}^{-}$ & $65-<68$ & 0 & 0 & 10 & 7.8 \\
\hline $\mathrm{D}^{+}$ & $60-<65$ & 27 & 16.66 & 10 & 7.8 \\
\hline $\mathrm{D}$ & $50-<60$ & 12 & 7.40 & 12 & 9.4 \\
\hline $\mathrm{F}$ & Less than 50 & 2 & 1.2 & 16 & 12.59 \\
\hline Total & & 162 & 100 & 127 & 100 \\
\hline
\end{tabular}

The table - 1 reveals the Partner's written quiz scores of $2^{\text {nd }}$ and $3^{\text {rd }}$ year nursing students and it is also expressed in the percentage. There are 66 students (40 percentage) obtained grade $\mathrm{A}$ in $2^{\text {nd }}$ year where as 25 students (nearly 20 percentage) have acquired grade $\mathrm{A}$ in $3^{\text {rd }}$ year which is the noteworthy feature. Almost the 'A' grade was doubled in $2^{\text {nd }}$ year compared with $3^{\text {rd }}$ year. When considering the failure rate of the $2^{\text {nd }}$ years, only 2 students (1 percentage) had failed however there are 16 students (12 percent) are failed in 3rd year. There is lot of fluctuations observed between other grades. It also can be interpreted that, in both the groups, nearly 70 percentage of the students have scored $\mathrm{A}, \mathrm{A}-, \mathrm{B}+, \mathrm{B}, \mathrm{B}-, \mathrm{C}+, \mathrm{C}$ and $\mathrm{C}$ - grades which is the good indicator. Although the scores resembling more or less similar in almost all the grades, the overall the performance of the $2^{\text {nd }}$ year is better than the 3 rd year students. Considering " $A$ " grade and " $F$ " grade this conclusion was arrived. The $\mathrm{z}$ test reveals that effectiveness of the Partners method is significant $(p=0.001)$, hence it indicates that the level of performance of the $2^{\text {nd }}$ year is better than $3^{\text {rd }}$ year.

\section{Discussion}

The present study shows almost 70 percent of the students have scored grade more than 65 percentage of the marks which is a peculiar feature proving that this method is effective for both the groups. The failure rate 
is a crucial indicator in any educational setting. Nearly 99 percentage of the $2^{\text {nd }}$ year students have passed similarly 88 percentage of $3^{\text {rd }}$ year students have passed respectively in the written quiz scores. Henceforth it can be concluded that the performance of $2^{\text {nd }}$ year is better than $3^{\text {rd }}$ year nursing students however, both the groups have increased their level of academic performance in "Partners" method.

None of the studies compared the cooperative methods between two groups whereas few studies have been done comparing the cooperative method with the traditional (Lecture) method. There are many studies reveals that the cooperative learning is applicable for all discipline. (Sapon\& Duncan, 2002).

Furthermore Jean Gumms (2001) examined the study where the concept of cooperative learning was applied to nursing theoretical content in an effort to increase student's knowledge, decrease attrition rates in a first level medical surgical course, and enhance communication skills. Increased knowledge was assessed by student's performance in the examinations. Although the studies in nursing are in sparse, some studies proved that this method is effective increasing the academic level of knowledge among nursing students (Linda 1995, Huff 1997, Susan 2002, Daodee 2006, Rani 2007, \&Hanson 2011).

In addition to that California Department of Education (2002) insists that the cooperative learning, not only enhances academic achievement, but also improves inter group relationships. Students learn how to depend on one another and help each other.

Yazici (2005) identifies that in his study conducted in University of Pittsburgh school of Nursing Pennsylvania, showed that comparing the student's midterm and final examination grades, those students taught using cooperative learning methods had an increase in both their midterm and final examinations by $10 \%$ and $15 \%$ respectively, when compared with other groups taught in the past 2 years using traditional methods.

\section{Limitation}

The study was limited to Oman Nursing Institute only. Another possible limitation is "Partners" method was done for only for one class session for both the groups. Although the study as limited generalizability, the study does facilitate to that this "Partners" method is effective.

\section{Recommendation}

The study can be done in all the nursing institutes of Oman. It also can be compared with traditional method. This method can be used for the entire semester or course for more conclusive result and to see the better outcome.

\section{Conflict of Interest}

None

\section{Conclusion}

Educationist and thinkers all over the world view education as critical factor in raising the standard of living of millions all over the globe. Therefore the type and mode of education rendered to the growing population needs to keep abreast with growing technocracy and mold the learners to combat with upcoming needs of the society. Education being subsystem of a larger social order it is always under review for adjustment. Adjustment doesn't drive for fluctuations rather command flexibility in the ongoing system. The process of acceleration in the education system is highly adaptable as it is or with minor modifications. Irrespective of fact that the teaching modes should meet the students need, the education at no cost can be compromised for the quality (Premkmar, 2010).

The Nursing discipline is growing and it is complex. The nursing education needs to accomplish problem solving, critical thinking skills thereby improving the student's academic achievement. In this study, the Arab nursing students improved their knowledge through "Partners "which is an innovative teaching method. We need to implement many innovative teaching styles like cooperative teaching and make the learning student centered. It is believed that collaborative learning promotes a larger educational agenda, one that encompasses several intertwined rationales. Every method has limitation of its own. The mixture of innovative methods needs to be incorporated to make teaching student friendly.

\section{References}

[1]. Amos \& White M.J.(1998).Teaching Tool: PBL. Nursing Educator, 23(2), 11-15.

[2]. Bradshaw, M. J. \& Arlene, J. L. (2001). Innovative Teaching strategies inNursing \&Related Health Profession, $5^{\text {th }}$ Edition, USA: Jones and Bartlett Publishers LLC.

[3]. Brady and Tsay.(19 ${ }^{\text {th }}$ Feb 2010) Cooperative Learning. Retrived May 21, 2010 from wn.com/Cooperative _ learning cached

[4]. Biggs,L.(2006). Interactivity in class engages students.Retirived from http://campustechnology.com/articles/2006/03/interactivity-in-class-engages- students.aspx

[5]. Beers, G.W. (2005). The Effect of Teaching Method on Objective Test Scores: PBL Vs Lecture. Journal of Nursing Education, $44,7,305-309$ 


\section{Is "Partners" (Cooperative Teaching and Learning) Method an effective Innovative teaching method}

[6]. Bowles, K. (2000). The relationship of critical thinking skills and the clinical judgment skills of Baccalaureate nursing students. Journal of Nursing Education, 44, 305-309.

[7]. California Department of Education, (2002).Retrieved from, www.cde.ca/gov/belst/ss/documents/england/vstnd/pdf.

[8]. Daodee,S.,Crabtree,K., Vandenberghe, R.(2006).Improving critical thinking of nursing students through cooperative learning. Thai Journal of Nursing Research, 10(1), 46-58.

[9]. Damodran, V \&Rangarajan.V (2007). Innovative methods of Teaching. Retrieved April 4, 2011, from http://math.arizona.edu/ atp- mena/conference/proceedings/Damodharan_Innovative_Methods.pdf- Cached

[10]. DGET, Mission Statement. Retrieved May 26,2010, from www.moh.gov.om/nv_menu.php?fNm=education/index.htm...1

[11]. Forneris,S.G. (2004). Exploring the attributes of critical thinking: A Conceptual Basis, International Journal of Nursing Education Scholarship, 1(1), .20.

[12]. Hanson Mary Jane.S.,\& Dona Rinaldi Carpenter. (2011). Integrating Cooperative Learning into Classroom Testing: Implications for Nursing Education and Practice, Nursing Education Perspectives, 32(4), 270-273.

[13]. Huff,C.(1997). Cooperative Learning: A model for teaching, Journal of Nursing Education,36(9),434- 437.

[14]. Jean Gumms.(2001).The effect of cooperative learning on students enrolled in a level 1 medical surgical nursing course. Journal of Cultural Diversity, 8(2), Proquest, pg 45.

[15]. Johnson .D, Johnson. R. \&Stanne (2000). Cooperative Learning: Theory, Principles, and Techniques. Retrieved May 19, 2010, from www.readingmatrix.com/conference/pp/proceedings/jacobs.pdf

[16]. Johnson, D. \& Johnson, R. (2002). An Overview of Cooperative Learning. .Retrieved April 3, 2010 from http://www.clcrc.com/pages.cl.html.

[17]. Kagon Spencer,. (1994). CooperativeLearning. Retrieved April 23, 2010 from hbe.com.au

[18]. Linda, M.G. (1995). Cooperative Learning Strategies, An Effective Method Of Teaching Nursing Research. Nurse Educator, 20(4), 26-29.

[19]. Lois.H.Neuman et al., (2009). What does an Innovative teaching assignment strategy mean to nursing students? Nursing Education Perspectives, 30(3), 159-163.

[20]. MujibulHasanSiddiqui,(2008). Models of Teaching. APH Publishing Company, New Delhi.

[21]. National League for Nursing. (2003). Position statement on innovation in nursing education: vision of nursing education,. Retrieved November 16, 2006, from http://www.nln.org/aboutnln/position statements/innovation.htm.

[22]. Pardue,K.T., Tagiliareni, M.E., Valiga,T., Davison-Price,M., Orehowsky,S., \& Task Group on Innovation in Nursing Education. (2005). Substantive innovation in nursing education: Shifting the emphasis from content coverage to student learning. Nursing Education Perspectives, 26, 55-57.

[23]. Premkumar.T. (2010) A study on the effectiveness of cooperative learning method based on the achievement level of the $11^{\text {th }}$ standard students in maths. M.Ed Thesis.

[24]. Rani Kanthan, and Sheryl Mills.(2007). Cooperative learning in the first year of undergraduate medical education. World Journal of Surgical Oncology, 5 (16), 1-7.

[25]. Sapon, S. A. \& Duncan. (2002). Ability Differences in Teaching and Learning in InclusiveClassrooms. Retrieved May 26,2010, from, www.sig2.hawaii.edu/resources/briefings/topic7/downloads/.../Article01.pdf-

[26]. Slavin, (1995). Teaching Concepts: Cooperative Learning, Retrieved March 4, 2010, from www.college.cengage.com/education/pbl/tc/coop.html - Cached

[27]. Slavin.R.E. (1990).Cooperative Learning: Theory, research, and practice. New Jersey: Prentice Hall.

[28]. Slavin.R.E. (1991). Student team learning: A practical guide to cooperative learning. Washington, D.C.: National Educational Association.

[29]. Susan,L.Copp., (2002). Using Cooperative Learning Strategies to teach Implications of the Nurse Practice Act. Nurse Educator. 27,(5),236-241.

[30]. Yazici, H. (2005). A study of collaborative learning style and team learning performance. Education and Training, 47, $216-229$. 